\title{
ASSESSMENT OF HEAD INJURY CRITERIA AND CHEST SEVERITY INDEX FOR FRONTAL IMPACT
}

\author{
M.S. Salwani ${ }^{*}$, B.B. Sahari ${ }^{2,3}$, Aidy $\mathrm{Ali}^{4}$ and A.A. Nuraini ${ }^{2}$ \\ ${ }^{1}$ Faculty of Mechanical Engineering, Universiti Malaysia Pahang \\ 26600 Pekan, Pahang Darul Makmur, Malaysia. \\ *Email: salwani@ump.edu.my \\ Phone: +6094246334; Fax: +6094246222 \\ ${ }^{2}$ Department of Mechanical and Manufacturing Engineering \\ Faculty of Engineering, Universiti Putra Malaysia \\ 43400 Serdang Selangor, Malaysia. \\ ${ }^{3}$ Institute of Advanced Technology, Universiti Putra \\ Malaysia, 43400 Serdang Selangor, Malaysia. \\ ${ }^{4}$ Department of Mechanical Engineering, \\ Faculty of Engineering, Universiti Pertahanan Nasional \\ Malaysia, Kem Sungai Besi, 57000 Kuala Lumpur, Malaysia.
}

\begin{abstract}
In this study, head injury criteria (HIC) and chest severity index (CSI) assessments are made based on finite element simulation. Simulations are carried out through nonlinear finite element analysis software LS-Dyna. The effect on the occupant's injury of introducing aluminum alloy, AA5182, to automotive side members is highlighted in comparison to the existing model made of steel. The HIC and CSI are taken as the evaluation criteria. The injury criteria are assessed under two impact conditions: full frontal and oblique. The aim of this paper is to analyze the effect of lightweight materials on occupant crash protection. It was shown that the introduction of AA5182 provides a $30.77 \%$ reduction in mass while improving the HIC and CSI performance in full frontal impact; whereas only CSI is improved in oblique impact.
\end{abstract}

Keywords: Impact; lightweight; finite element; head injury criterion; chest severity index.

\section{INTRODUCTION}

The study of the crash characteristics and the lightweight design of automotive side members has been an important aspect of crash safety, and a series of research achievements have been made. Efforts were made to improve and optimize the design in terms of weight efficiency and crush energy absorption [1, 2]. A hat-type automotive side member made of aluminum alloy was investigated by considering the crosssectional shape, internal stiffening and foam-filling. Li Y et al. [3] introduced a method of making automobile body parts lightweight using lower-depth high-strength steel sheets, to replace the original design of mild steel, while under the constraint of retaining the crashworthiness of the parts. Various simplified models of automotive side members using a hybrid component made of steel and aluminum have been studied [4]. Numerical studies on automotive side members using hybrid materials to reduce the peak impact force while increasing the total absorbed energy of the component have 
also been carried out [5]. The literature shows that substantial effort has been devoted to investigating the crash performance of lightweight designs but none of the mentioned literature includes occupant injury assessment [1-5]. Occupant protection in a crash is a crucial factor in the substitution of materials in automotive parts. Salwani et al. [6] focused on the crash performance of aluminum automotive side members subjected to oblique impact without addressing occupant injuries and [7] assessed injury only for frontal impact. The objective of this paper is to highlight the effect of lightweight materials on occupant crash protection for both oblique and frontal impact. The crash performance of the steel model is analyzed first then an aluminum alloy is introduced by using AA 5182 for the automotive side member. Last, occupant safety is assessed using the chest severity index (CSI) and head injury criterion (HIC). The injury criteria are assessed under two impact conditions: full frontal and oblique.

\section{METHODOLOGY}

\section{Geometric Model}

The automotive side member in this study is a thin-walled hat-section column as shown in Figure 1. The side member consists of the outer side member and inner side member spot welded together. The front end of the side member is connected to the cross member and the front bumper beam.
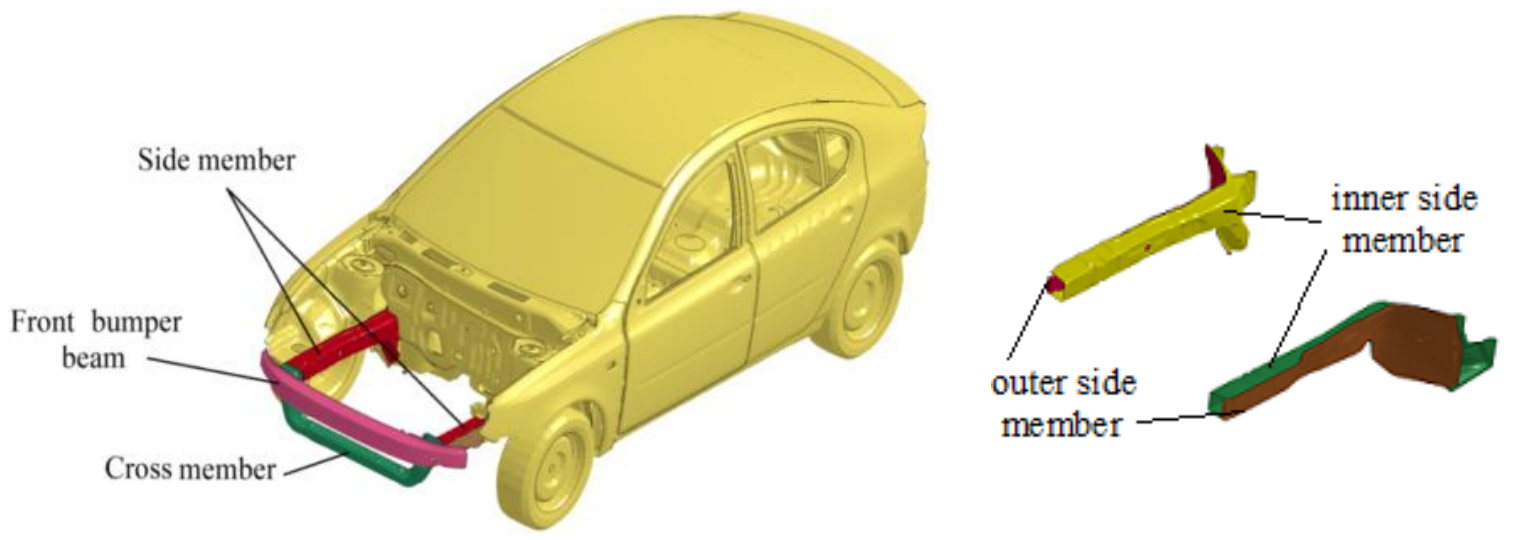

Figure 1. Automotive side member.

The thicknesses of the inner side member, $t_{\text {inner }}$, and outer side member, $t_{\text {outer }}$, for the steel model are 1.6 and $1.4 \mathrm{~mm}$, respectively and the length is $800 \mathrm{~mm}$. For the aluminum model, the thicknesses of the inner side member, $t_{\text {inner, }}$ and outer side member, $\mathrm{t}_{\text {outer, }}$ are 2.8 and $3.7 \mathrm{~mm}$, respectively. In this study, dynamic numerical simulation is carried out using the nonlinear finite element (FE) code LS-Dyna 971. This geometrical model is meshed using Hypermesh software. The element size is 10 $\mathrm{mm}$ and is modelled using 4-node shell elements. The automotive side member is developed using the Belytschko-Tsay shell element and spot welding was represented by the beam element. 


\section{Boundary Conditions}

Various crash tests for occupant safety have been prescribed by the National Highway Traffic Safety Administration (NHTSA). In addition to the available regulations, other types of crash test, for instance far-side occupant injury, are comprehensively assessed by [8]. However, this study is in accordance with the Federal Motor Vehicle Safety Standard (FMVSS) 208 which prescribed 0 to $48 \mathrm{~km} / \mathrm{h}$ and an impact angle of $0^{\circ}$ to $30^{\circ}$ for the frontal rigid barrier test. In this analysis, a rigid wall is set at an angle of $30^{\circ}$ under the oblique impact test. The car moves at an initial velocity, V equal to $48 \mathrm{~km} / \mathrm{h}$ and impacts a rigid wall.

\section{Materials Model}

The materials used in the model and their mechanical properties are shown in Table 1. Material type 100 (*SPOTWELD) is used to define the mechanical properties of the spot weld and material type 98 (*SIMPLIFIED_JOHNSON_COOK) is used to model the behavior of the aluminum alloy under impact loading, and the input constants were obtained from the experimental work of [9].

Table 1. Types of materials used and their mechanical properties [10]

\begin{tabular}{lllllr}
\hline Model & Part & Material & $\begin{array}{c}\mathrm{E} \\
{[11]}\end{array}$ & $v$ & $\begin{array}{l}\mathrm{S}_{\mathrm{y}} \\
(\mathrm{MPa})\end{array}$ \\
\hline \multirow{2}{*}{ Steel } & Inner & SPRC35 & 206.0 & 0.30 & 233 \\
& Outer & SAPH370F & 206.0 & 0.30 & 254 \\
\multirow{2}{*}{ Aluminum } & Inner & AA5182 & 69.6 & 0.33 & 135 \\
& Outer & AA5182 & 69.6 & 0.33 & 135 \\
\hline
\end{tabular}

\section{Dummy model}

A large variety of crash test dummies is available to represent the different sizes and shapes of humans. In this study, the dummy is modelled with a combination of some coarsely meshed deformable parts and rigid parts. This approach simplifies the dummy and keeps the runtime low while providing reasonably good performance. In the present dummy, the head is modeled with solid elements and the skin is represented by viscoelastic material. The head form is closed with a base plate and is made nondeformable by assigning rigid material. Overall the head form mass is about $4.6 \mathrm{~kg}$. Crash testing into a rigid barrier with adult dummies was performed at a speed of 48 $\mathrm{km} / \mathrm{h}$. Inside the vehicle, a 50\%-Hybrid III dummy was placed on the driver's seat in the belted condition. Validation of the Hybrid III FE dummy simulated in LS-Dyna shows encouraging results where the time history response matched well both in magnitude and timing $[12,13]$. The dummy used in the simulation contained accelerometers, the device to measure the acceleration in a particular direction. This data can be used to determine the probability of injury.

Important measures of occupant injury from mechanical impact, used by automobile and other industries, are the CSI and HIC. The HIC value can be obtained using Equation (1) [14]. The magnitude of linear acceleration observed at the center of the head upon impact is denoted by $a(t)$. 


$$
\mathrm{HIC}=\max \left[\left(\frac{1}{t_{2}-t_{1}} \int_{t_{1}}^{t_{2}} a(t) \mathrm{d} t\right)^{2.5}\left(t_{2}-t_{1}\right)\right]
$$

Also $t_{1}$ and $t_{2}$ denote the two time points in the resultant acceleration of duration $\mathrm{T}$ such that $0 \leq t_{1}<t_{2} \leq T$. The values of $t_{1}$ and $t_{2}$ are obtained so as to maximize Equation (1). Thus, HIC is an acceleration-based value and is obtained from the time versus acceleration pulse. A dummy equivalent of HIC value, denoted by HIC(d), is given as [15]:

$$
\mathrm{HIC}(d)=166.4+0.75446 \times \mathrm{HIC}
$$

\section{RESULTS AND DISCUSSION}

In this study, the total weights of the automotive side members made of steel and aluminum were 14.56 and $10.08 \mathrm{~kg}$, respectively. From the simulation performed, the amount of energy absorbed by the automotive side member in both models is shown in Figure. 2. This figure infers that the use of aluminum alloy offers a great reduction in the weight of the automotive components while retaining the energy absorption capability of the steel. For restrained drivers, the CSI parameter proved to be a strong predictor of occupant injury because it reflects the way the front end of the car is crushed [16]. Based on the general requirements by the NHTSA in FMVSS No 208 for occupant crash protection, the bio-mechanical load limits in impact load cases for a $50 \%$ -Hybrid III dummy cannot exceed $60 \mathrm{G}$ for CSI and 700 for HIC15 and 1000 for HIC36 (2004) [2-10, 12-17]. Figure 3 shows that the model with an aluminum side member subjected to frontal collision conforms with the regulation as the acceleration did not exceed the $60 \mathrm{G}$ limit.

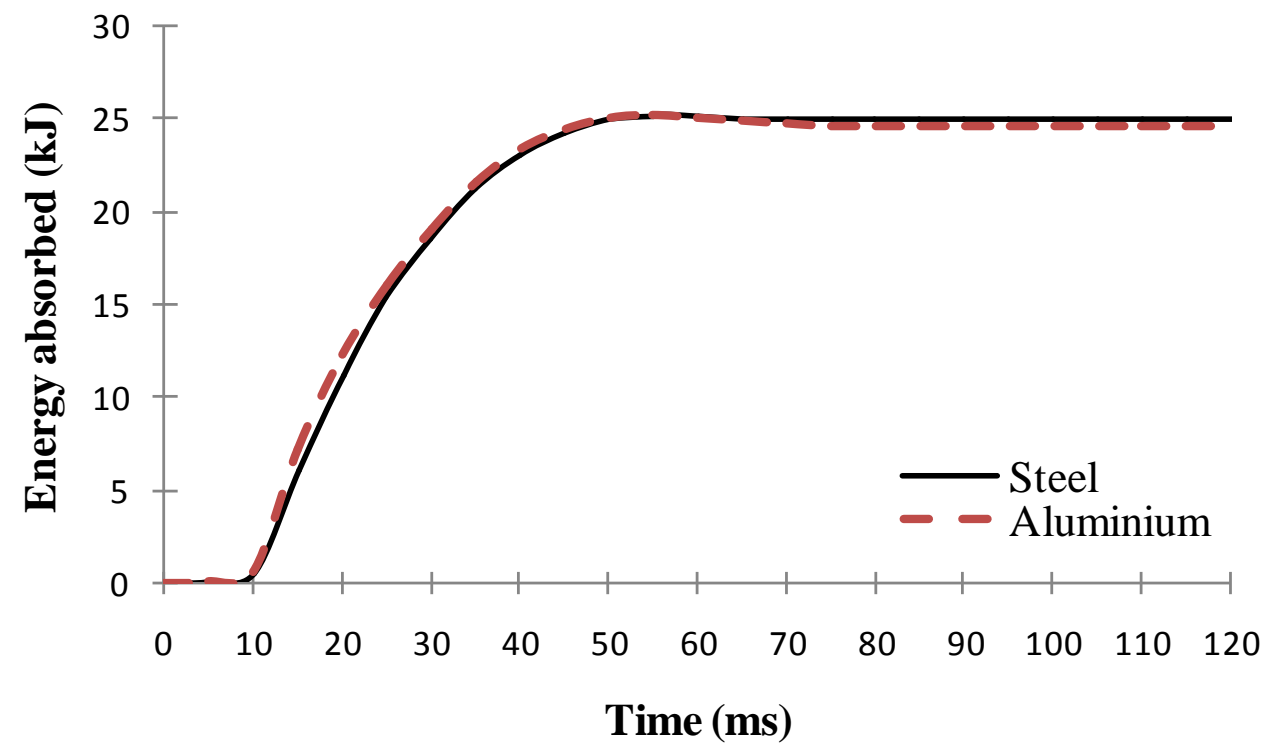

Figure 2. Energy absorbed 


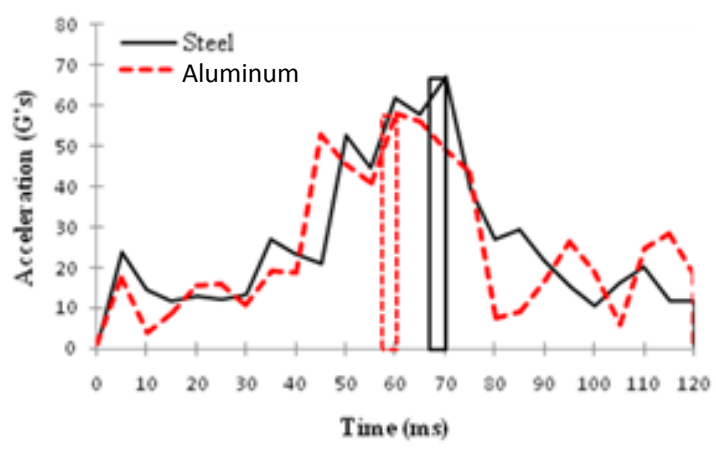

(a)

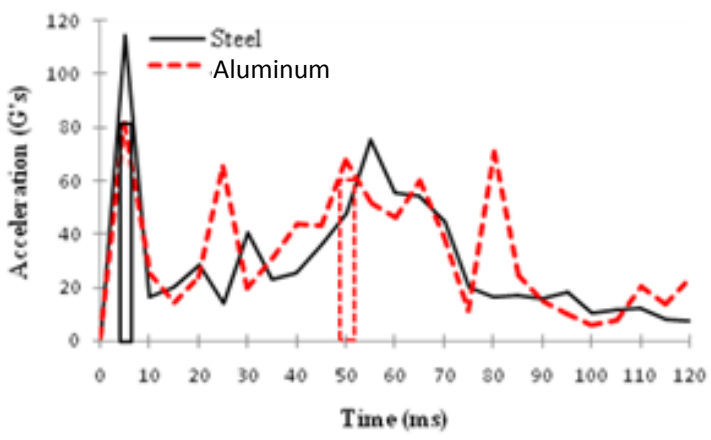

(b)

Figure 3. CSI value obtained from the dummy model (a) full frontal impact and (b) oblique impact

HIC 15

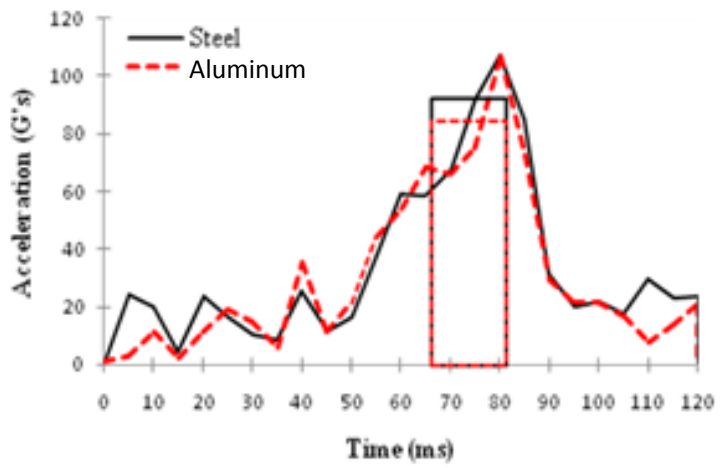

HIC 15

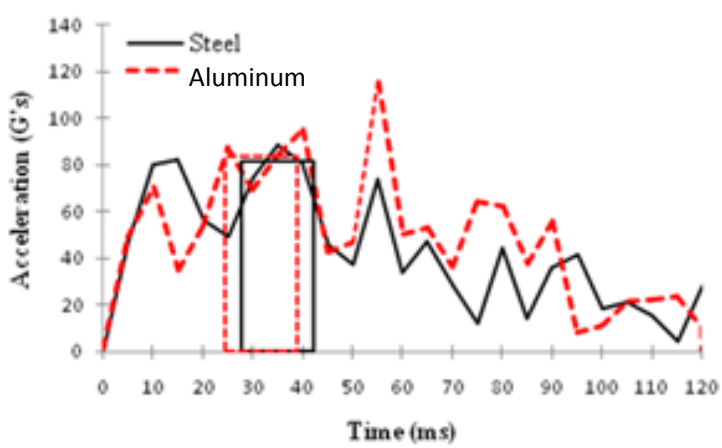

(b)

Figure 4. Values obtained from the dummy model (a) full frontal and (b) oblique impacts.

Occupant safety, however, is highly threatened as the acceleration of the car with the aluminum side member exceeds the limit in the oblique collision. The sudden impact of the shoulder with the door causes severe injury to the occupant, reflected by the approximately double value of the CSI, see Table 3. Head injuries remain among the most frequent and severe injuries sustained by vehicle occupants in road accidents and 
account for approximately $40 \%$ of road fatalities in the European Union[18]. Figure 4 shows the acceleration pattern for cars with steel and aluminum side members. HIC15 and HIC36 respond to the acceleration in $15 \mathrm{~ms}$ and $36 \mathrm{~ms}$ time intervals, respectively, at the highest value. Peak acceleration is observed in Figure 3 due to the contact between the dummy's chest and the steering, and the dummy's shoulder and the door, for full frontal and oblique impacts, respectively. A summary of both injury criteria is shown in Table 2. The car with an aluminum side member indicated lower injury potential in all criteria assessed for full frontal impact and only CSI for oblique impact. On the other hand, the steel side member is superior in terms of HIC in an oblique collision. Despite the improvement shown by the aluminum side member, neither member, steel nor aluminum, complied with the limit set by NHTSA with respect to HIC performance.

Table 2. Summary of occupant injury prediction for different types of side member

\begin{tabular}{lcccccc}
\hline Model & \multicolumn{3}{c}{ Full frontal } & \multicolumn{3}{c}{ Oblique } \\
\cline { 2 - 7 } & CSI & HIC15 & HIC36 & CSI & HIC15 & HIC36 \\
\cline { 2 - 7 } Steel & 795.6 & 1165.0 & 1474.0 & 1450.0 & 741.2 & 1414.0 \\
Aluminum & 700.6 & 924.9 & 1305.0 & 1416.0 & 875.3 & 1624.0 \\
\hline
\end{tabular}

\section{CONCLUSIONS}

In this study, the performance of an aluminum alloy side member was analyzed in terms of occupant safety. It can be concluded that for the same mass, a side member made of AA5182 is capable of absorbing almost the same amount of energy as steel. The introduction of AA5182 provides a $30.77 \%$ weight reduction and lower potential for occupant injury in CSI, HIC15 and HIC36 in full frontal impact and CSI in oblique impact. Future research can include high-strength steel as another lighter material option in automotive design.

\section{ACKNOWLEDGEMENTS}

The authors would like to thanks Universiti Malaysia Pahang and Universiti Putra Malaysia for providing financial assistance and laboratory facilities under project (RDU1303114).

\section{REFERENCES}

[1] Kim HS, Wierzbicki T. Effect of the cross-sectional shape of hat-type crosssections on crash resistance of an "S"-frame. Thin-Walled Structures. 2001;39:535-54.

[2] Kim HS. Analysis of crash response of aluminium foam-filled front side rail of a passenger car. International Journal of Crashworthiness. 2001;6:189-208.

[3] Liu Y, Koops GH, Strathmann H. Characterization of morphology controlled polyethersulfone hollow fiber membranes by the addition of polyethylene glycol to the dope and bore liquid solution. Journal of Membrane Science. 2003;223:187-99. 
[4] Hosseini-Tehrani P, Nikahd M. Two materials S-frame representation for improving crashworthiness and lightening. Thin-Walled Structures. 2006;44:407-14.

[5] Zhou Y, Lan F, Chen J. Crashworthiness research on S-shaped front rails made of steel-aluminum hybrid materials. Thin-Walled Structures. 2011;49:291-7.

[6] Salwani M, Ali A, Sahari B, Nuraini A. Crash of automotive side member subjected to oblique loading. International Journal of the Physical Sciences. 2011;6:7125-31.

[7] Salwani MS, Sahari B, Ali A, Nuraini A. The Effect of Automotive Side Member Filling on Car Frontal Impact Performance. Journal of Mechanical Engineering and Sciences. 2014;6:873-80.

[8] Fildes B, Digges K. Occupant crash protection in far-side crashes. Monash University Accident Research Centre; 2010. p. 162.

[9] Smerd R, Winkler S, Salisbury C, Worswick M, Lloyd D, Finn M. High strain rate tensile testing of automotive aluminum alloy sheet. International Journal of Impact Engineering. 2005;32:541-60.

[10] Lee H, Kim N, Lee TS. Overload failure curve and fatigue behavior of spotwelded specimens. Engineering Fracture Mechanics. 2005;72:1203-21.

[11] Eitssayeam S, Intatha U, Rujijanagul G, Pengpat K, Tunkasiri T. Structural and electrical properties characterization of $(1-\mathrm{x}) \mathrm{PbZr0}$. 52Ti0. 48O3-xBaFe0. 5Nb0. 5 O3 system. Applied Physics A. 2006;83:295-9.

[12] Mohan P, Park C-K, Marzougui D, Kan C-D, Guha S, Maurath C, et al. LSTC/NCAC dummy model development. 11th International LS-Dyna Users Conference2010.

[13] Tabiei A, Lawrence C, Fasanella EL. Validation of finite element crash test dummy models for predicting orion crew member injuries during a simulated vehicle landing. NASA Technical Manual No NASATM-2010-215476. 2009.

[14] Gong SW, Lee HP, Lu C. Computational simulation of the human head response to non-contact impact. Computers \& Structures. 2008;86:758-70.

[15] Deb A, Gupta NK, Biswas U, Mahendrakumar MS. Designing for head impact safety using a combination of lumped parameter and finite element modeling. International Journal of Crashworthiness. 2005;10:249-57.

[16] Deck C, Willinger R. Improved head injury criteria based on head FE model. International Journal of Crashworthiness. 2008;13:667-78.

[17] Jones IS, Whitfield RA. Predicting injury risk with "New Car Assessment Program" crashworthiness ratings. Accident Analysis \& Prevention. 1988;20:411-9.

[18] Standards FMVS. Title 49 - Transportation, Chapter V - National Highway Traffic Safety Administration. Department of Transportation, Part 571: U. S. Government Printing Office; 2004. 